\title{
International law and the military use of unmanned maritime systems
}

Article

Accepted Version

Schmitt, M. N. and Goddard, D. S. (2017) International law and the military use of unmanned maritime systems.

International Review of the Red Cross, 98 (902). pp. 567-592. ISSN 1607-5889 doi:

https://doi.org/10.1017/S1816383117000339 Available at https://centaur.reading.ac.uk/89740/

It is advisable to refer to the publisher's version if you intend to cite from the work. See Guidance on citing.

To link to this article DOI: http://dx.doi.org/10.1017/S1816383117000339

Publisher: Cambridge University Press (CUP) for International Committee of the Red Cross

All outputs in CentAUR are protected by Intellectual Property Rights law, including copyright law. Copyright and IPR is retained by the creators or other copyright holders. Terms and conditions for use of this material are defined in the End User Agreement.

www.reading.ac.uk/centaur

\section{CentAUR}


Central Archive at the University of Reading

Reading's research outputs online 


\title{
International Law and the Military Use of Unmanned Maritime Systems ${ }^{1}$
}

\author{
Michael N. Schmitt \& David S. Goddard
}

Contents

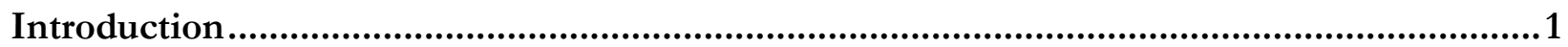

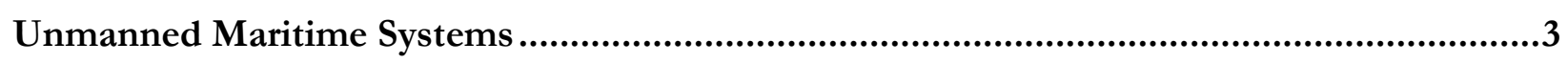

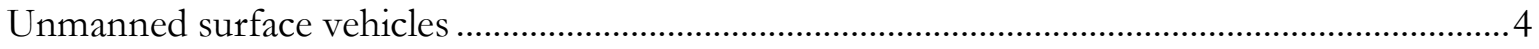

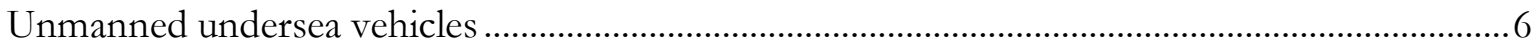

Legal Status of Unmanned Maritime Systems .................................................................8

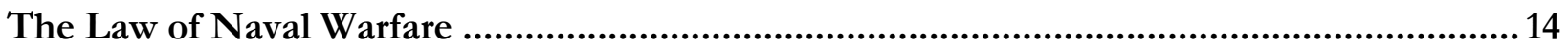

Legal Review of Unmanned Maritime Systems ...............................................................................14

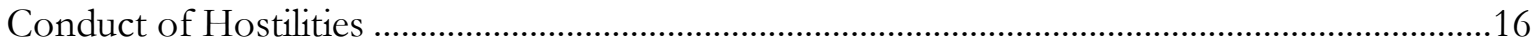

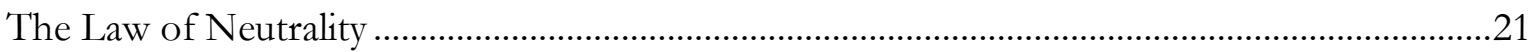

\section{Introduction}

On 15 December 2016 Chinese forces seized an unmanned underwater vehicle being operated by a U.S. government vessel, the USNS Bowditch, 50 nautical miles from the Philippine coast in the South China Sea. ${ }^{2}$ In response, the U.S. government demanded the return of the device, which it said had been 'conducting routine operations in accordance with international law', and which it claimed was a 'sovereign immune vessel of the United States.' ultimately resolved swiftly and peacefully, with the return of the device some five days later. ${ }^{4}$ Yet, behind the diplomatic language lie some interesting legal questions. How does international law

\footnotetext{
1 The authors are appreciative to Professor Wolff Heintschel von Heinegg for his assistance during the preparation of this article. Views expressed herein are solely those of the authors in their personal capacities and do not necessarily represent those of any organization with which they are affiliated.

2 The incident was widely reported. See, e.g., US Says Chinese Warship Seized Navy Underwater Drone, NEW YORK TIMES (Dec. 16, 2016), http://www.nytimes.com/aponline/2016/12/16/us/politics/ap-us-navy-drone.html.

${ }^{3}$ U.S. Department of Defense, Statement by Pentagon Press Secretary Peter Cook on Incident in South China Sea (Dec. 16, 2016), https://www.defense.gov/News/News-Releases/News-Release-View/Article/1032611/statement-bypentagon-press-secretary-peter-cook-on-incident-in-south-china-sea [hereinafter DoD Statement on USNS Bowditch Incident].

4 See, e.g., Jane Perlez \& Matthew Rosenberg, China Agrees to Return Seized Drone, Ending Standoff, Pentagon Says, NEw YORK Times (Dec. 17, 2016), http://www.nytimes.com/2016/12/17/world/asia/china-us-drone.html; Chris Buckley, Chinese Navy Returns Seized Underwater Drone to U.S., NEW YORK Times (Dec. 20, 2016), http://www.nytimes.com/2016/12/20/world/asia/china-returns-us-drone.html.
} 
regulate the use of such systems? And do they benefit from sovereign immunity, as vessels or otherwise? $^{5}$

More generally, the use of unmanned systems, together with the possibility that autonomous unmanned systems are likely to come of age soon, has drawn widespread attention in the legal community. Much of this attention has centred on their use in combat. Of note are the vibrant, and often emotive debates, surrounding the use of air and ground unmanned systems to conduct socalled 'targeted killings' and to counter improvised explosive devices in populated areas, respectively. Beyond these debates, the armed forces of many States are increasingly turning to unmanned systems for intelligence, surveillance, and reconnaissance (ISR) purposes and for transportation and other aspect of military logistics.

However, there has been little consideration of the legal issues raised by the growing use of unmanned maritime systems (UMS). This is certain to change, for although the operational use of such systems lags well behind that of their air and ground counterparts, in future maritime security operations and naval warfare such use will loom very large. For instance, UMSs will greatly expand the monitoring capability of law enforcement and naval forces during counter-piracy, counter-drug, counter-weapons of mass destruction proliferation, and refugee operations. During wartime, they are particularly promising with respect to improving transparency of the maritime battlespace, enhancing anti-access/area denial (A2/AD) capabilities, and anti-submarine and anti-mine warfare. And during both peacetime and periods of armed conflict, UMSs are likely to prove themselves invaluable in maintaining the security of the fragile sea lanes of communication upon which global economic prosperity depends.

This article examines the key legal issues surrounding the use of the systems for military purposes. Although many of the same issues are implicated by civil activities involving UMSs, no effort shall be made to develop them in that context. Moreover, the article is not intended to delve deeply into the contentious issues raise by autonomous, particularly lethal, maritime systems, although when appropriate they shall be highlighted. In that the United States is currently the leader in the development and use of UMSs, heavy use is made of US doctrine and reference is often to its systems. Other States are, however, engaged in their own development and fielding programs, generally along the same lines as those pioneered by the United States. Finally, as to naval warfare, the discussion is limited to the law applicable in international armed conflicts, as it is with respect to such conflicts that the law most highly developed. That said, many of the legal norms discussed below, especially those regarding the conduct of hostilities, apply mutatis mutandis during noninternational armed conflicts.

Discussion begins with a broad stroke explanation of the systems and their likely missions. The groundwork laid, the legal status of UMSs is examined, alongside the rights and obligations that the status may entail. Attention then turns to an analysis of how the law of naval warfare and the law of neutrality govern UMS activities during international armed conflicts. As will become apparent,

\footnotetext{
${ }^{5}$ For attempts at answering some of these questions, see, e.g., James Kraska \& Raul "Pete" Pedrozo, China's Capture of U.S. Underwater Drone Violates Law of the Sea, LAwFARE (Dec. 16, 2016), https://www.lawfareblog.com/chinas-captureus-underwater-drone-violates-law-sea; Julian Ku, The Nonexistent Legal Basis for China's Seizure of the U.S. Navy's Drone in the South China Sea, LAwFARE (Dec. 16, 2016), https://www.lawfareblog.com/nonexistent-legal-basis-chinas-seizure-usnavys-drone-south-china-sea.
} 
several important issues remain unsettled as a matter of international law. Therefore, subsequent State physical or verbal practice will be especially important with respect to clarifying the legal parameters and content of the various legal regimes affecting UMS use for military purposes.

\section{Unmanned Maritime Systems}

Unmanned maritime systems are not an entirely new phenomenon. For instance, they have been used for mine-clearing and battle damage assessment since the Second World War, notably in Vietnam and during Operation Iraqi Freedom in 2003. Interestingly, they were also used to conduct radiation testing following nuclear tests. ${ }^{6}$ However, it is only in the $21^{\text {st }}$ century that they became the subject of energetic technological progress and operational concept development. To illustrate, while the US defence budget for unmanned air systems remained constant between 2011 and 2015, funding allocated to UMSs increased over 300\%. ${ }^{7}$ As the inaugural Director of the US Navy's unmanned warfare systems has observed, the goal is to fully embed unmanned technology in naval operations by 'mainstreaming' it because unmanned assets will enable naval forces to 'understand quicker, act faster, and adapt continuously'.

Advancing technologies will certainly expand the resort to UMSs. ${ }^{9}$ Indeed, over time, they may fully supplant manned assets in performing certain missions, for they offer a number of advantages over manned systems. Among them are cost; endurance, a key capability in performing tracking missions; persistence in an area, which allows for greater ISR coverage; an ability to operate with great stealth, an important attribute, for example, when resupplying special forces operating covertly ashore; and the freeing up of personnel to perform other essential functions. Of course, like their air and ground counterparts, they offer an alternative to operations that place personnel at risk in hostile environments. Additionally, in that UMSs do not need the infrastructure to support onboard personnel, the transportation capacity of unmanned systems typically exceeds that of equally sized manned surface vessels or submarines. Perhaps most significantly, the future is certain to witness the collaborative use of UMSs within networks, along the lines of the US Navy's Integrated Undersea Surveillance System (IUSS), established to monitor large swaths of the oceans and provide early warning and information superiority in the maritime domain.

Yet, UMSs also have disadvantages relative to manned systems. They are more reliant on communications in the sense that a loss of a communications link can sometimes disable them entirely, or at least impair their functionality or usefulness. Additionally, UMSs may have design limitations that render them ineffective in certain circumstances to which the crews of manned

6 U.S. DePartment of Defense, Unmanned Systems InTEgrated RoAdmap FY2011-2036, at 25 (2011),

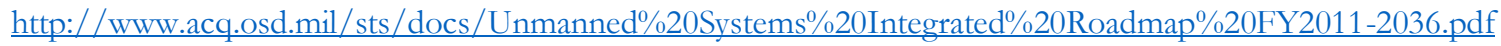

[hereinafter U.S. DoD Roadmap]; U.S. Department of the Navy, The Navy Unmanned Surface Vehicle (USV) MASTER PLAN 1 (2007), http://www.navy.mil/navydata/technology/usvmppr.pdf [hereinafter U.S. NAVY USV MASTER Plan].

7 U.S. DOD ROADMAP, above note 6, at 16.

8 Megan Eckstein, Interview: Rear Admiral Robert Girrier on the Future of the Navy's Unmanned Systems, USNI NEWs (Oct. 12 , 2016), https://news.usni.org/2016/10/12/22016.

9 See, e.g., U.S. Department of Defense, Defense Science Board, Task Force Report: The Role of AutOnOmy IN DoD Systems 17-18 (2012), https://www3.nd.edu/ dhoward1/autonomy.pdf [hereinafter 2012 AUTONOMY REPORT]. 
systems might be better able to react. Similarly, manned systems are generally more adaptive to situations that might not have been considered when developing equivalent UMSs.

Unmanned maritime systems can be characterized as unmanned surface vehicles (USVs) or unmanned undersea vehicles (UUV). The categories bring different characteristics to bear in maritime operations and are subject to specific limitations. USVs are generally better able to communicate because communications underwater are highly challenging. Thus, as Rand has noted, 'USV s could be highly effective in overcoming challenging A2/AD environments, particularly in C4 ISR, military deception, information operations, electronic warfare, and cyberwarfare missions. ${ }^{10}$ Further, because USVs operate from the surface they are more versatile in the sense of engaging in activities, such as surveillance or reconnaissance, with respect to the water column, surface, and superjacent air space. By contrast, the stealth capabilities of UUVs tend to be significantly greater than those of USV because the very features that limit communications underwater can act to shield UUVs from detection.

\section{Unmanned surface vehicles}

As presently envisaged by the US Navy, the primary USV missions, in priority order are: mine countermeasures (MCM), anti-submarine warfare (ASW), maritime security (MS), surface warfare (SUW), special operations forces (SOF) support, electronic warfare (EW), and maritime interdiction operations (MIO) support. ${ }^{11}$ The first, mine countermeasures is conducted to clear large areas at sea in which to operate safely, maintain transit routes and lanes, and open areas in which operations are about to be conducted, particularly those in shallow waters where manned mine sweepers cannot support littoral operations such as amphibious landing. Various methods can be employed to perform these functions. Sweden and Finland, for instance, use systems that mimic the acoustic and magnetic signature of surface vessels to detonate mines. ${ }^{12}$ Other concepts of operations include a USV that deploys a remotely operated vehicle (ROV), which propels itself to a suspected mine, verifies it as such, and launches a submunition to destroy the mine. Another involves the deployment into a mined area, by a USV transporter, of a UUV capable of placing charges on mines. ${ }^{13}$ The ultimate objective is for USVs to perform all four countermine functions - detection, identification, localization, and neutralization - in a single sweep. ${ }^{14}$

USVs can likewise perform submarine countermeasures. For instance, they can accompany a manned surface group to identify submarines, track them, and, in some cases, attack them ('Maritime Shield'), thereby minimizing a significant threat to the group, as well as reducing the requirement for manned surface vessels, submarines, or aircraft to perform the anti-submarine function. They can execute the same tasks to clear routes ahead of a surface group's transit ('Protected Passage'). Although somewhat less suitable for the mission, USV may also carry out

\footnotetext{
10 Scott SAVitz ET AL., U.S. NAvy Employment Options for UnManNed Surface Vehicles (USVs) 39 (2013), http://www.rand.org/content/dam/rand/pubs/research_reports/RR300/RR384/RAND_RR384.pdf.

11 U.S. NAVY USV MASTER PLAN, above note 6, at 11.

12 antoine Martin, Unmanned Maritime Systems: Global Review of Technology, Roadmaps, Roles, Challenges \& OpPORTUnities, AND PREDictions 5 (undated), http://www.uvs-consulting.com/wpcontent/uploads/2014/01/AUVSI-Aug-13-UMS-Global-Review-UVSC.pdf.

13 U.S. NAVY USV MaSTER Plan, above note 6, at 19.

14 U.S. NAVy USV Master Plan, above note 6, at 18.
} 
'Hold at Risk' missions, which involve monitoring submarines considered to be a potential threat as they leave port or pass through a chokepoint. ${ }^{15}$

In their maritime security role, USVs can be launched from a host platform or from ashore to collect information through their onboard sensors. Data is transmitted back to the operating forces either continuously, in real-time, or when the system ascertains that certain pre-defined criteria (like the existence of a specified threat) have been met. Such operations may involve directing the USV against a specified vessel(s), or putting it on patrol within a demarcated area. USVs may also take a more direct role in maritime security operations. Examples include warning away vessels by means of a 'loud-hailer', marking them with paint balls or radio tags, and engaging them with onboard guns, missiles, or torpedoes. ${ }^{16}$ The same capabilities can be employed to execute the surface warfare mission.

USVs may support special operations by, for example, providing ISR, transporting or infiltrating/exfiltrating SOF forces, maintaining a presence in the vicinity of a SOF operation to provide security, and resupplying forces ashore. ${ }^{17}$ Their use for electronic warfare includes providing warnings of ongoing electronic attack, as well as deception and jamming. Examples of the latter include ruses such as the use of a False Target Generator, spoofing, and local area network jamming. ${ }^{18}$ However, because of their typically low profile, USVs lack the 'height of eye' to engage in such activities over long distances. Finally, USVs may assist in maritime interception operations. Scenarios illustrating this role include: conducting an initial approach of a suspect vessel to determine if it is hostile by, for example, drawing fire; monitoring all sides of a vessel being boarded to provide situational awareness and check that cargo is not being jettisoned or that its crew is not escaping; checking the underside of the vessel with sensors, or possibly a small UUV, to identify trapdoors, moon pools, drop tanks, and other features; and using onboard sensors to find and locate hidden cargo, such as groups of trafficked individuals or chemical, biological, nuclear, radiological, or explosive material. ${ }^{19}$

An illustration of USV technology is the wave glider, which can be deployed to operate autonomously or semi-autonomously. The device seized by the Chinese in the USNS Bowditch incident is an example of the technology, and was described by the Department of Defense as being used to collect 'military oceanographic data such as salinity, water temperature, and sound speed'. Wave gliders use paddles suspended from the hull to benefit from wave energy and employ solar panels to power their instrumentation and communications equipment, as well as multiple sensors. In part because of their energy independence, such devices are suitable for long-range, longendurance missions that can last a year or more. Further, wave gliders are stealthy because they are acoustically silent and have a low profile relative to the ocean's surface. The systems are considered especially promising with respect to gathering and transmitting data for ISR and anti-submarine

\footnotetext{
15 U.S. NAVy USV Master Plan, above note 6, at 23-24.

16 U.S. NAVY USV MASTER PLAN, above note 6, at 34.

17 The Combined Joint Operations from the Sea Centre of Excellence (CJOS/COE), Study (2009) For MARITIME UnMANNED SYSTEMS (MUS) IN NATO 32 (2009), http://www.cjoscoe.org/images/MUS in NATO.pdf [hereinafter CJOS/COE STUDY].

18 U.S. NAVY USV MaSTER Plan, above note 6, at 45.

19 U.S. NAVY USV MaSTER PLAN, above note 6, at 48.

20 Statement on USNS Bowditch Incident, above note 3.
} 
warfare purposes, as well as Rapid Environmental Assessment in littoral warfare and bathymetric surveying. ${ }^{21}$

Numerous USVs are presently in various stages of development. Prominent among these is the 'Sea Hunter' ACTUV (anti-submarine warfare continuous trail unmanned vehicle). Costing a mere $\$ 23$ million, the Sea Hunter is a 40-metre trimaran that is capable of operation in rough seas, can travel at 31 knots, operates autonomously (with a man on the loop) for three months at a time, and abides by the rules of safe navigation. Capable of patrolling up to 10,000 nautical miles of ocean, the system uses its own sensors to locate submarines, such as the very quiet diesel electric variants operated by China and Russia, before following them from as far as two miles away, while providing regular updates on its target's location and activities. ${ }^{22}$ Although the Sea Hunter may be armed with torpedoes, as presently conceived a human command is necessary to launch them. ${ }^{23}$ The same system is also being considered for use in mine countermeasures and other missions.

\section{Unmanned undersea vehicles}

An unmanned undersea vehicle is a 'self-propelled submersible whose operation is either fully autonomous (pre-programmed or real-time adaptive mission control) or under minimal supervisory control and is untethered except, possibly, for data links such as a fiber optic cable'. ${ }^{24}$ As with their surface counterparts, such systems can engage in, or facilitate, a wide array of missions. Of note are ISR, mine countermeasures, ASW, inspection/identification, oceanography, serving as a communication/navigation network node, payload delivery, information operations, and timecritical strike. ${ }^{25}$ For instance, UUVs can be employed to gather oceanographic data prior to operations on 'winds, bathymetry, water visibility, current waves, bottom geophysical parameters, kelp concentrations, sand bars, etc. to determine minable areas'; detect (e.g., by using optical and sonar sensors) and neutralize mines; deploy and retrieve devices, such as sensors, underwater; transport material needed during SOF operations; and engage in spoofing (as in acting as a submarine decoy or creating the impression that multiple submarines are in an area, thereby making it inaccessible to an adversary), jamming, and other electronic warfare activities. ${ }^{26}$ Like USVs, they are capable of supporting the Maritime Shield and Protected Passage missions, and, given their stealth, they are well-suited to the Hold at Risk mission, particularly with respect to monitoring submarines. ${ }^{27}$

21 Fastwave, Submission to Defence White Paper 2015: Unmanned Maritime Systems, n.p. (2015), http://www.defence.gov.au/Whitepaper/docs/256-Fastwave.pdf.

22 Rick Stella, Ghost Ship: Stepping Aboard the Sea Hunter, The Navy's Unmanned Drone Ship, Digital TrendS (Apr. 11, 2016), http://www.digitaltrends.com/cool-tech/darpa-officially-christens-the-actuv-in-portland/; Rachel Courtland, DARPA's Self-Driving Submarine Hunter Steers Like a Human, IEEE SPECTRUM (Apr. 7, 2016), http://spectrum.ieee.org/automaton/robotics/military-robots/darpa-actuv-self-driving-submarine-hunter-steers-like-ahuman.

23 Arhur Villasanta, DARPA's Sea Hunter Killer Drone will make China's Submarines More Vulnerable, YIBADA (July 28, 2016), $\quad$ http://en.yibada.com/articles/146010/20160728/darpa-s-sea-hunter-killer-drone-will-make-chinasubmarines.htm.

24 U.S. Department of the Navy, The Navy Unmanned Undersea Vehicle (UUV) Master Plan 4 (2004), http://www.navy.mil/navydata/technology/uuvmp.pdf [hereinafter U.S. NAvY UUV MASTER PLAN].

252012 AUTONOMY REPORT, above note 9, at 85-86.

26 U.S. NAVy UUV MASTER Plan, above note 24, at 11; CJOS/COE STUDY, above note 17, at 24

27 U.S. NAVy UUV Master Plan, above note 24, at 12. 
UUVs bring several unique features to bear in naval operations. They tend to have a low acoustic and electromagnetic signature, thereby rendering them hard to detect. Even when surfaced to raise a transmission antenna, their low profile makes them difficult to locate by sight or radar. Thus, employing them can contribute to maintaining the element of surprise. UUVs may also be more persistent than a surface vessel because they are less susceptible to rough weather and resultantly can remain on-station for extended periods despite poor sea conditions. Many UUVs are relatively small, thereby enhancing the ease with which they may be carried and deployed from aircraft, ships, and USVs; in some situations, a single platform can deploy multiple UUVs capable of acting in concert. Relatedly, their size makes them easily recoverable and reusable. Should UUVs fail, they merely settle to the bottom, where they can be recovered so long as the water is not too deep. Small size and the difficulty of detection also make UUVs ideal for operating in shallow waters. Finally, they are, except for a nuclear submarine, the only undersea system capable of operating beneath the polar ice cap. ${ }^{28}$

Particularly attractive is the capacity of UUVs to engage in mining. For instance, the U.S. Defense Science Board has highlighted their utility in 'cascaded operations'. ${ }^{29}$ Today's offensive sea mining capabilities are limited, but UUVs could provide a means to significantly extend capabilities by increasing the influence range via mobility. Extra-large UUVs could be deployed from one or more shore sites or surface ships, and autonomously travel to an area of operations. Once the UUVs arrive, they could deploy smaller UUVs or variants of modular torpedoes that have both automated target recognition capabilities and enough explosive material to disrupt or disable (or possibly even destroy) surface vessels. The UUV modular torpedoes would essentially serve as intelligent mines that can manoeuvre in an area and disrupt or disable adversary ships upon target verification. This would enable friendly forces to restrict the adversary's freedom of movement and control access to key maritime areas, such as chokepoints and harbors. UUVs also could be used to stop enemy ships from returning to port, thus precluding replenishment.

Another possible application for UUVs is in tapping, or disrupting, communications cables running along the ocean floor. Such cables carry all manner of signals and data, both military and civilian, across the oceans, traversing vast distances at often great depths. They are a lucrative target for States wishing to gain intelligence about their rivals or enemies, or, in times of tension, to hamper or prevent the flow of information. ${ }^{30}$ UUVs, unencumbered by onboard human operators, present an attractive means for achieving these objectives.

Numerous UUV variants are under development. Illustrative is the Chinese Haiyan. The Haiyan can operate at depths up to 1,000 meters, travel at 4 knots, and sustain operations for a month. It carries multiple sensors that enable it to perform missions such as surveillance of submarines, undersea patrols, mine-sweeping, and, in certain configurations, anti-surface warfare. ${ }^{31}$ Russian development of UUVs apparently includes a 'nuclear delivery drone' capable of transporting a

28 CJOS/COE STUDY, above note 17 , at 24-25.

29 U.S. Department of Defense, Defense Science Bohrd, Summer Study on Autonomy 61-62 (2016), http://www.acq.osd.mil/dsb/reports/DSBSS15.pdf [hereinafter 2016 STUDY ON AUTONOMY].

30 See, e.g., Bruce Dorminey, How Bad Would It Be If The Russians Started Cutting Undersea Cables? Try Trillions In Damage, FORBES (Nov. 2, 2015), http://www.forbes.com/sites/brucedorminey/2015/11/02/russian-navy-probing-u-sundersea-communications-cables-in-new-global-threat/\#6b625ac766b1.

312016 STUDY ON AUTONOMY, above note 29, at 43. 
nuclear payload up to 6,200 nautical miles, deep underwater, at speeds of up to 56 knots. ${ }^{32}$ Its assumed purpose would be to attack coastal targets. In the United States, Boeing has developed the Echo Voyager, a 51-foot autonomous UUV that can operate for months at a time. The system, which is undergoing sea trials, uses a hybrid rechargeable power system, has a modular bay that allows it to employ differing payloads, and surfaces to transmit information back to friendly forces, thereby obviating the need for physical tethers to maintain communications links. The system is expected to perform undersea surveillance and mine-detection, as well as other missions. ${ }^{33}$

\section{Legal Status of Unmanned Maritime Systems}

The issue of the legal status of unmanned maritime systems is divisible into two sub issues, status as a ship (or vessel) and status as a warship. Both are complex and somewhat unsettled.

There is no accepted definition of a 'ship' or 'vessel' in the law of the sea. Indeed, both terms appear in this body of law, apparently without distinction, and sometimes in the same treaty, as is the case with the UN Convention on the Law of the Sea (LOSC) ${ }^{34}$ For the purposes of this article, the term 'ship' will be used. Qualification as a ship is particularly important, as ships enjoy certain navigational rights, and shoulder various obligations, not enjoyed by other entities that operate on, in, or above the water, such as aircraft.

Although the LOSC does not define the term 'ships', when reading the instrument in the context of its own text, as is appropriate pursuant to Article 31 of the Vienna Convention on the Law of Treaties, ${ }^{35}$ it appears to consider that ships are manned. For instance, pursuant to Article 94 of the LOSC, flag States must ensure that each ship flying its flag is in the charge of a master and officers who possess appropriate qualifications, in particular in seamanship, navigation, communications and marine engineering, and that the crew is appropriate in qualification and numbers for the type, size, machinery and equipment of the ship [and] that the master, officers and, to the extent appropriate, the crew are fully conversant with and required to observe the applicable international regulations concerning the safety of life at sea, the prevention of collisions, the prevention, reduction and control of marine pollution, and the maintenance of communications by radio. ${ }^{36}$

Some treaties do define ships, albeit in ways that complicate matters. For instance, the 1952 Convention for the Prevention of Pollution of the Sea by Oil (as amended) defines a ship as 'any sea-going vessel of any type whatsoever, including floating craft, whether self-propelled or towed by another vessel, making a sea voyage ${ }^{37}$; the 1973 Convention for Prevention of Pollution from Ships (as amended) provides that a ship is 'a vessel of any type whatsoever operating in the marine environment $[. .$.$] includ[ing] hydrofoil boats, air-cushion vehicles, submersibles, floating craft and$

\footnotetext{
32 Kyle Mizokami, Pentagon Confirms Russia Has a Submarine Nuke Delivery Drone, Popular MeCHANICS (Dec. 8, 2016), http://www.popularmechanics.com/military/weapons/a24216/pentagon-confirm-russia-submarine-nuke/.

33 Kevin McCaney, Boeing's New Autonomous UUV Can Run for Months at a Time, Defense Systems (Mar. 14, 2016), https://defensesystems.com/articles/2016/03/14/boeing-echo-voyager-uuv.aspx.

34 United Nations Convention on the Law of the Sea, Dec. 10, 1982, 1833 U.N.T.S. 397 [hereinafter LOSC].

35 Vienna Convention on the Law of Treaties art. 31(1)-(2), May 23, 1969, 1155 U.N.T.S. 331 [hereinafter VCLT].

${ }^{36}$ LOSC, above note 34, art. 92(4)(b)-(c).

371962 Amendments to the 1952 Convention for Prevention of Pollution of the Sea by Oil art. 1(1), Apr. 11, 1962, 600 U.N.T.S. 332.
} 
fixed or floating platforms ${ }^{38}$; and the 1996 Protocol to the London Dumping Convention (as amended) states that "[v]essels and aircraft" means waterborne or airborne craft of any type whatsoever." 39 Taking a different approach is the Convention on International Regulations for Preventing Collision at Sea (COLREGS), which applies to 'every description of water craft, including non-displacement craft and seaplanes used or capable of being used as a means of transportation on water, ${ }^{40}$ and the Convention on Conditions for Registration of Ships (not yet in force), which extends to 'any self-propelled sea-going vessel used in international seaborne trade for the transport of goods, passengers, or both'.

As is apparent, it is not possible to unequivocally characterize UMSs as ships, at least with respect to the application of maritime treaties. As they are unmanned, it is arguable that the LOSC is inapplicable to them. By contrast, the 1952 Convention on the Prevention of Pollution takes a highly inclusive approach by imposing no such requirement and encompassing even floating seagoing craft that are unpropelled. The 1973 Pollution Convention and the 1996 Protocol to the London Dumping Convention are likewise inclusive. All three would extend to many UMSs. Some UMSs will be capable of transporting goods and persons on the sea and therefore would be subject to the Collision Regulations, whereas those not engaged in that activity and UUVs would not be reached by the instrument. And the Registration Convention would apply to UMSs used for transportation, but would not appear to pertain to other UMSs, even if they have that capability.

The differing approaches are understandable because the definitions are crafted for the purposes of the individual instruments. Thus, for instance, the pollution conventions adopt a broad definitional approach since their object and purpose is to limit pollution at sea to the extent feasible, whereas the COLREGs are intended to regulate navigation on the surface of the water and therefore do not reach submerged submarines or UUVs. Accordingly, when determining the applicability of a treaty to UMSs, fidelity must be paid to the instrument's scope and definitional provisions.

The LOSC presents a special case in that it lays out the crucial, and foundational, maritime navigational regime, but contains no definitional provision and is therefore subject to interpretive dissonance. As noted, it would appear the instrument is meant only to apply to manned seaborne craft. This interpretation may be challenged, however, because, given the size and capabilities of some prospective UMSs, interpreting the instrument teleologically as applicable to them based on the Convention's object and purpose of establishing a comprehensive legal regime at sea makes some sense. Such an assertion invites the counter-argument that States Parties may wish to limit certain rights that would attach to UMSs if they qualify as ships, such as the rights of innocent, transit, and archipelagic passage, by taking a narrower approach. Therefore, it will be particularly important to monitor State practice regarding the characterization of UMSs because 'any subsequent

\footnotetext{
38 International Convention for Prevention of Pollution from Ships of 1973, as amended by the 1978 Protocol, art. 2(4), Feb. 17, 1978, 1340 U.N.T.S. 61, 184.

${ }^{39}$ Protocol to the Convention on the Prevention of Marine Pollution by Dumping of Wastes or other Matter art. 1(6), adopted 7 Nov. 96, 36 I.L.M. 1 (entered into force 24 Mar. 06). See also Convention on the Prevention of Marine Pollution Convention on the Prevention of Marine Pollution by Dumping of Wastes and other Matter art. III(2), Dec. 29, 1972,1046 U.N.T.S. 138.

${ }^{40}$ Convention on the International Regulations for Preventing Collisions at Sea r. 3(a), Oct. 20, 1972, 28 U.S.T. 3459, T.I.A.S. No. 8587, 1050 U.N.T.S. 16.

41 United Nations Convention on Conditions for Registration of Ships art. 2(4), Feb. 7, 1984, UN Doc. TD/RS/CONF/19/Add.l, at 2 (not yet in force).
} 
practice in the application of the treaty which establishes the agreement of the parties regarding its interpretation' is relevant as to the Convention's proper interpretation. ${ }^{42}$ Such practice may be both physical, as in the case of UMSs exercising the passage rights of ships, or verbal, for instance through government statements that purport to interpret it. At the present, any definitive conclusion as to the instrument's applicability to UMSs would be premature. ${ }^{43}$

Further complicating matters is the fact that it is widely accepted by States that many provisions of the LOSC are reflective of customary international law. The content and interpretation of customary law shifts and develops over time through State practice and opinio juris. Therefore, a colourable argument may be fashioned that, irrespective of the correct interpretation of the LOSC, UMSs are ships pursuant to customary international law and they may accordingly enjoy, and are subject to, the navigation and other rights and obligations of customary law, which in great part are reflected in the Convention. To illustrate, an argument could be made that even if a State Party's UMS has no right of innocent passage through the territorial sea pursuant to the LOSC, it nevertheless enjoys such a right pursuant to customary international law. The absence of State practice and opinio juris on the matter makes such an argument tenuous, but it must be remembered that customary international law develops by States asserting rights and obligations that did not previously exist.

The U.S. position is interesting in this regard, for, although a non-Party to the LOSC, the United States is of the view that many of the treaty's provisions, including those governing navigation, reflect customer international law. ${ }^{44}$ The 2007 US Navy/Marine Corps/Coast Guard's Commander's Handbook on the Law of Naval Operations labels UMSs as 'other naval craft'. However, it is anticipated that the 2017 update of the Manual also will refer to them not only as such craft, but also as 'vessels', consistent with the language used by the Department of Defense in stating its position following the USNS Bowditch incident. ${ }^{45}$ Doing so will render the Handbook internally consistent in the sense that the new version is also expected to confirm that UUVs and USVs enjoy the navigational rights of ships, such as innocent and transit passage. By the same logic, they would have the other key navigational rights and obligations, such as freedom of the high seas, enjoyed by ships. The position taken by the United States is likely to encourage other States to follow suit.

If UMSs do enjoy navigational rights, then they will be bound by the conditions associated with those privileges. For example, during innocent, transit, and archipelagic sealanes passage, a UMS would be required to proceed continuously and expeditiously, ${ }^{46}$ and to refrain from any activities other than those incident to their passage, especially the threat or use of force against the coastal State. $^{47}$ Innocent passage carries further restrictions. Those of most relevance to UMSs include prohibitions on: exercise or practice with weapons; the collection of information to the prejudice of the coastal State; acts of propaganda; the launching, landing, or taking on board of any military device; research and survey activities; and interference with communications systems, a category that would include underwater communications cables. ${ }^{48}$ Furthermore, while UMSs entitled to exercise

42 VCLT, above note 35, art. 31(3)(b).

${ }^{43}$ For a contrary view, see, e.g., Kraska \& Pedrozo, above note 5.

44 Office of the General Counsel, U.S. Department of Defense, Law of War Manual \13.1.2 (June 2015, updated Dec. 2016) [hereinafter U.S. DOD MANUAL].

45 Statement on USNS Bowditch Incident, above note 3.

46 LOSC, above note 34, arts. 18(2), 38(2), 53(3).

${ }^{47}$ LOSC, above note 34, arts. 19(2), 39(1), 54.

${ }^{48}$ LOSC, above note 34, arts. 19(2). 
transit or archipelagic passage would be allowed to do so in their normal mode, ${ }^{49}$ which may be submerged for a UUV, during innocent passage all underwater vehicles must be on the surface. ${ }^{50}$

As well as the question of qualification as a ship and entitlement to navigational rights, it is also necessary to ascertain whether UMSs can have the status of warships. The requirements for such status were first set forth in the 1907 Hague Convention VII, ${ }^{11}$ and are today replicated in Article 29 of the LOSC: "warship" means a ship belonging to the armed forces of a State bearing the external marks distinguishing such ships of its nationality, under the command of an officer duly commissioned by the government of the State and whose name appears in the appropriate service list or its equivalent, and manned by a crew which is under regular armed forces discipline.' The conditions are universally recognized and there is little question but that they have acquired customary international law status. ${ }^{52}$

It would be difficult to interpret the definition to include a UMS. Assuming arguendo that it qualifies as a ship, the system could easily be part of the inventory of the armed forces and appropriately marked. However, it would be necessary to stretch the notion of command by a commissioned officer to include remote control of its activities. Moreover, as UMSs are unmanned (or at best, manned remotely), on a plain text reading of the requirement to be manned by a crew subject to military discipline they do not qualify as warships. In time, these criteria may shift or soften, but, as things presently stand, even if UMSs qualify as ships, they cannot be warships.

Notwithstanding these difficulties, warship status is less important during peacetime than might at first appear. It is true that under the LOSC warship status affords certain rights. For instance, warships may seize a pirate ship; ${ }^{53}$ visit a ship on the high seas suspected of engaging in piracy, slave trade, unauthorized broadcasting, being without nationality, or flying a foreign flag (or showing no flag) when it is actually of the nationality of the ship conducting the visit; ${ }^{54}$ conduct hot pursuit; ${ }^{55}$ and engage in enforcement measures designed to safeguard the marine environment. ${ }^{56}$ However, each of these rights is granted equally to other ships that are 'clearly marked and identifiable as being on government service and authorized to that effect. ${ }^{57}$ The LOSC imposes no further criteria, meaning that there is no inherent reason why a UMS could not be duly authorized by a government to exercise each of the peacetime rights enjoyed by warships, so long as it is marked accordingly and, crucially, qualifies as a ship.

Similarly, while the LOSC recognises the sovereign immunity of warships, essentially the same privileges are afforded to other vessels on government non-commercial service. Both categories are protected from the enforcement jurisdiction of other States and are inviolable in the sense that they

49 LOSC, above note 34, arts. 39(1)(c), 54.

${ }^{50}$ LOSC, above note 34, art. 20.

51 Convention No. VII Relating to the Conversion of Merchant Ships into War-ships arts. 2-6, Oct 18, 1907,205 Consol. T.S. 319.

52 See, e.g., San Remo Manual on International Law Applicable to Armed Conflicts at Sea (Louise Doswald Beck ed., 1995) $113(\mathrm{~g})$.

53 LOSC, above note 34, art. 107.

${ }^{54}$ LOSC, above note 34, art. 110.

55 LOSC, above note 34, art. 111(5).

${ }^{56}$ LOSC, above note 34, art. 224.

57 LOSC, above note 34, arts. 107, 111(5), 224. Similarly, art. 110(5) provides for the right of visit to be exercised by 'other duly authorized ships or aircraft clearly marked and identifiable as being on government service.' 
may not be boarded, seized, or otherwise interfered with. Only one LOSC provision on immunity is written as applying to warships alone. Under Article 30, if a warship fails to comply with the laws and regulations of a coastal State in whose territorial sea it is operating, then the coastal State may require it to leave. However, considering the broad immunity already enjoyed by government vessels on non-commercial service, it is hard to imagine what additional enforcement action could be taken against them. Therefore, so long as a UMS qualifies qualify as a ship and is operated by a government for exclusively non-commercial purposes, it will enjoy effectively the same sovereign immunity under the LOSC as a warship.

The issue of sovereign immunity becomes more difficult to resolve if UMSs do not qualify as ships in the first place. The German Naval Manual takes the position that UMSs enjoy sovereign immune status to the extent that they are controlled from a ship that itself enjoys such status. ${ }^{58}$ This much seems clear. However, the United States goes further by asserting that 'USVs and UUVs engaged exclusively in government, noncommercial service are sovereign immune craft. USV/UUV status is not dependent on the status of its launch platform. ${ }^{59}$ While, as discussed above, the United States appears to moving towards a clear assertion of the status of UMSs as ships, the reference here to the immunity of 'craft' suggests a reliance on the immunity enjoyed by State property in general. This is a well-established, if poorly understood, principle, ${ }^{60}$ which must be respected in the law of the sea as an example of 'other rules of international law', to which key provisions of the LOSC regime are subject. $^{61}$ In any case, so long as UMSs belong to the State and are solely engaged in noncommercial purposes, the U.S. position would appear to be sound.

Moving from the peacetime context, sovereign immunity of UMSs is less relevant during international armed conflict. The principles of immunity set out above do not apply between opposing belligerents because UMSs may qualify as military objectives irrespective of whether they enjoy sovereign immunity, and may therefore be attacked or seized as booty of war. ${ }^{62}$ Nevertheless, status as a warship is relevant for other purposes under the law of naval warfare. In periods of international armed conflict, they are the only vessels entitled to exercise belligerent rights, the most significant being the use of force against the enemy. Other rights control of neutral vessels in the

58 German Navy, SM 3, Commander's Handbook: Legal Bases for the Operations of Naval Forces 45 (2002) [hereinafter GERMAN COMMANDER'S HANDBOOK].

59 U.S. NAVY, U.S. MARINE CORPS \& U.S. COAST GUARD, NWP 1-14M/MCWP 5-12/COMDTPUB P5800.7A, THE COMmander's Handbook on the LAW of NAval Operations q 2.3.6 (2007) [hereinafter U.S. Commander's HANDBOOK].

${ }^{60}$ The principle is reflected in the United Nations Convention on Jurisdictional Immunities of States and Their Property, Dec. 2, 2004, G.A. Res. 59/38 (not yet in force). The Convention is based on draft articles adopted, with commentaries, by the International Law Commission (ILC). Int'l Law Comm'n, Rep. on the Work of its Forty-Third session, UN Doc. A/46/10, at 13 (1991). As the ILC notes, 'Ilegal theories abound as to the exact nature and basis of immunity. ... Beyond or around the hard core of immunity, there appears to be a grey area in which opinions and existing case law and, indeed, legislation still vary.' Id., at 23.

${ }^{61}$ LOSC, above note 34, arts. 2(3), 19(1), 21(1), 31, 34(2), 58(3), 87(1), 138, 293(1), 297(1)(b).

${ }^{62}$ As an object, UMS may generally be attacked so long as they meet the definition of a military objective. SAN REMO MANUAL, above note 52, $\mathbf{9}$ 40-41. To the extent that an enemy unmanned maritime system might be considered a vessel, even if it does not qualify as a warship, it is subject to capture and prize adjudication when outside neutral waters. SAN REMO MANUAL, above note 52, $\mathbf{q}$ 135-38. On booty of war, see 1 CUSTOMARY INTERNATIONAL HUMANITARIAN LAW rule 49 (Jean-Marie Henckaerts \& Louise Doswald-Beck eds., 2005) [hereinafter CIHL STUDY]. See also U.S. DoD

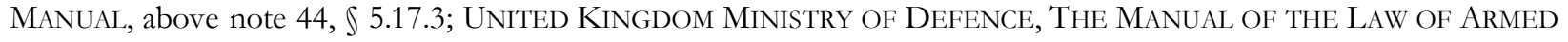
CONFLICT 11.88 (2004) [hereinafter UK MANUAL]. 
immediate vicinity of naval operations, ${ }^{63}$ visit and search of merchant ships outside neutral waters when the warship reasonably suspects the they are subject to capture, ${ }^{64}$ and enforcement of blockades. ${ }^{65}$

Notwithstanding the issues surrounding their legal status, UMSs are nevertheless envisioned as engaging in, or facilitating, many of the activities that depend on qualification as a ship or warship. The lack of status as such does not necessarily mean that UMSs may not engage in them. This is so in two regards.

First, UMSs may be launched from a ship to facilitate the functions it is entitled to perform. An example is the use of a USV to inspect the hull of a ship subject to the right of visit. Such usage is legally no different than the launch of ribbed boats to transfer a boarding team to the intercepted vessel. It is the ship which is exercising the right, not the UMS. Along the same lines, warships may transit an international strait and archipelagic sea lanes in 'normal mode'. ${ }^{66}$ While vessels in transit passage must 'refrain from any threat or use of force against the [coastal State]', ${ }^{67}$ it is well-accepted that they may use on-board helicopters to ensure the security of the ship during passage, since doing so is their 'normal mode' of operation. Unmanned maritime vessels could be deployed to perform an analogous function. Again, as a matter of law, it is the ship that is transiting in normal mode, not any UMSs involved.

A similar approach can be applied during an armed conflict. For example, a warship maintaining a line of blockade may use UMSs to perform surveillance functions in order to alert the ship to attempts by neutral vessels to breach the blockade. Again, it is the ship that is exercising the belligerent right to maintain a blockade during an armed conflict. More to the point, UMSs are both military equipment and 'means of warfare'. Thus, they may be employed in any circumstance in which it would be lawful to use other weapon systems, such as torpedoes, missiles or mines, especially during naval engagements on the high sea or operations in an adversary's territorial waters.

There are, however, limits to such an approach. Fundamentally, the control over the UMS must be such that, as a matter of fact, it is still the entitled ship that is exercising the right in question. Moreover, the use of the system has to be consistent with any restrictions on the right in question. Of particular relevance are those relating to innocent passage, during which 'the launching, landing or taking on board of any military device' is prohibited, ${ }^{68}$ as is 'any other activity not having a direct

\footnotetext{
${ }^{63}$ SAN REMO MANUAL, above note 52, $₫ 108$.

64 SAN Remo Manual, above note 52, $₫$ 118. The term 'merchant ship' (or vessel) is broadly interpreted. For instance, it is defined by the United Kingdom as 'a vessel that is not a warship, an auxiliary vessel, or other state vessel (such as a customs or police vessel) and that is engaged in commercial or private service'. UK MANUAL, above note 62 , ๆ $13.5(\mathrm{k})$. See also SAN REMO MANUAL, above note 52, 913 (i).

65 As set out in the San Remo Manual, '[a] blockade may be enforced and maintained by a combination of methods and means of warfare provided this combination does not result in acts inconsistent with the rules set out in this document.' SAN REMO MANUAL, above note 52, I 97. While this paragraph acknowledges the potential use of e.g. mines, the effective enforcement of a blockade generally requires, in practice, the exercise of the right of capture, which is reserved to warships. Ibid., 19 98, 118, 146(f).

${ }^{66}$ LOSC, above note 34, arts. 39(1)(c), 53(3).

${ }^{67}$ LOSC, above note 34, arts. 39(1)(b), 54.

${ }^{68}$ LOSC, above note 34, art. 19(2)(f).
} 
bearing on passage. ${ }^{99}$ Given these explicit prohibitions, the deployment of UMSs that do not, themselves, enjoy the right of innocent passage, would appear to be proscribed under that regime.

\section{The Law of Naval Warfare}

It is unquestionable that UMS operations are governed by the law of naval warfare during an international armed conflict, as are operations involving any other means of warfare. Indeed, the use of a UMS, including one that operates with a high degree of autonomy, to engage in hostilities against another State would initiate such an armed conflict. As noted in the ICRC's Commentary to the 1949 Geneva Conventions, 'Any difference arising between two States and leading to the intervention of armed forces is an [international] armed conflict ... even if one of the Parties denies the existence of a state of war. It makes no difference how long the conflict lasts, or how much slaughter takes place. ${ }^{70}$ Thus, even if a UMS conducted hostile operations only against another such system, the laws governing international armed conflict would apply.

\section{Legal Review of Unmanned Maritime Systems}

As noted, although it is difficult to characterize UMSs as warships, a UMS is undoubtedly a 'means of warfare' (weapons and weapons systems) to the extent it is capable of engaging in an activity that qualifies as an 'attack', such as anti-surface, anti-submarine, or mine-laying operations. ${ }^{71}$ The manner in which UMSs are, or are intended to be, employed are 'methods of warfare' (tactics).

Article 36 of Additional Protocol I provides that, '[i]n the study, development, acquisition or adoption of a new weapon, means or method of warfare, a High Contracting Party is under an obligation to determine whether its employment would, in some or all circumstances, be prohibited by this Protocol or by any other rule of international law applicable to the High Contracting Party.' Although the requirement to review means of warfare is customary in nature, controversy exists over whether that mandating review of 'methods of warfare' has achieved customary status. United States policy, for instance, only requires a review of weapons and weapons systems prior to acquisition. $^{72}$

${ }^{69}$ LOSC, above note 34, art. 19(2)(1).

70 Commentary to Geneva Convention I for the Amelioration of the Condition OF THE Wounded And SICK IN THE ARMED FORCES IN THE FIELD 32 (Jean Pictet ed., 1952). See also CommentARY TO GENEVA Convention II for the Amelioration of the Condition of the Wounded, Sick, AND Shipwrecked Members of Armed Forces at SeA 28 (Jean Pictet ed., 1960); Commentary to Geneva Convention III Relative to the Treatment of Prisoners of War 23 (Jean Pictet ed., 1960); Commentary to Geneva Convention IV Relative to the Protection of Civilian Persons in Time of War 20 (Jean Pictet ed., 1958).

${ }^{71}$ In international humanitarian law, an attack is defined as an '[act] of violence against the adversary, whether in offence or in defence'. Protocol Additional to the Geneva Conventions of 12 August 1949, and Relating to the Protection of Victims of International Armed Conflicts art. 49(1), June 8, 1977, 1125 U.N.T.S. 3 [hereinafter Additional Protocol I]. While the treaty definition applies only to attacks from the sea that are directed at the land or may affect civilians on land, it is widely accepted as applying to naval warfare, generally, as custom. SAN REMO MANUAL, above note 52, 9 13(b).

72 U.S. DoD Manual, above note 44, $\int$ 6.2. See also Program on Humanitarian Policy and Conflict Research,

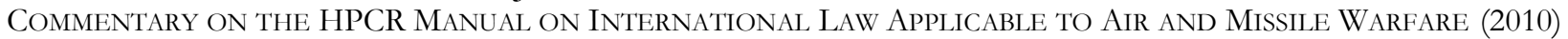
at Rule 9, 9 2; Tallinn Manual on the International Law Applicable to Cyber Warfare (Michael N. Schmitt ed., 2013), at Rule 48, 12. 
Weapon reviews are conducted based on the intended use of the weapon or weapon system in question, in the setting and situations in which it is expected to be employed. ${ }^{73} \mathrm{~A}$ central issue is its ability to engage in discriminate warfare, and, in this regard, the ban on 'a method or means of combat which cannot be directed at a specific military objective... and consequently, [is] of a nature to strike military objectives and civilians or civilian objects without distinction' looms large in a weapon review. ${ }^{74}$

In the UMS context, the sensors that identify a target are therefore likely to be the focus of the greatest attention, especially with respect to how they are affected by such factors as depth, temperature, visibility, salinity, and other features of the maritime environment. Most current UMSs, and systems nearing development, use sensors and weapons similar (or identical) to those already employed in naval operations, such as torpedoes, mines and guns. However, the fact that a UMS may do so does not alone suffice to meet the weapon review requirement, since the obligation is to assess the 'system' rather than its individual components. A proper weapon review will evaluate the performance of sensors and weapons as they operate in conjunction with each other, as well as the linkages to any decision-making functions of the UMS and/or to a human exercising remote control.

This assessment will include whether the 'unmanned' feature of the UMS in some way affects its ability to distinguish between lawful military objectives and unlawful targets, as is required by the principle of distinction. ${ }^{75}$ Being unmanned does not necessarily preclude or impede a system's ability to distinguish. In some cases, it might, as when the system's sensors are relatively rudimentary or are limited by external factors, such as rough seas or poor weather. In others, the absence of a human on-board may have no bearing on whether the UMS's sensors can adequately distinguish. Of course, whether a system's engagement process involves a human 'in the loop' (remotely controlling the engagement), 'on the loop' (monitoring the engagement with the ability to terminate it when necessary), or 'out of the loop' (the system performs autonomously) will have implications when gauging the ability of the UMS to comply with the principle.

It is also necessary to consider whether the intended use of a candidate UMS violates any specific weapons prohibitions. While UMSs, as a category, are not specifically regulated in international humanitarian law, they may share certain characteristics with weapons such as torpedoes or mines that are the subject of regulation. To the extent that this is so, they must comply with the relevant law. For instance, torpedoes, they must be rendered harmless once they have completed their attack run. ${ }^{76}$ Mines, similarly, must become harmless within an hour of control being lost over them. ${ }^{77}$ These requirements, intended to prohibit the use of 'dumb' weapons that would pose a hazard to

73 ICrC, A Guide to the Legal Review of New Weapons, Means and Methods of Warfare, Nov. 2006, at $\$$ 1.2 .

74 Additional Protocol I, above note 71, art. 51(4)(b) \& (c). On the customary law prohibition, see CIHL STUDY, above note 62, Rule 71 (Jean-Marie Henckaerts \& Louise Doswald-Beck eds., 2005) [hereinafter].

75 The principle of distinction requires that parties to a conflict 'all times distinguish between the civilian population and combatants and between civilian objects and military objectives and accordingly ... direct their operations only against military objectives'. Additional Protocol I, above note 71, art. 48. On the customary law status of the principle, see CIHL STUDY, above note 62, rule 1 . As to the maritime context, see SAN REMO MANUAL, above note 52 , 939.

${ }^{76}$ Convention No. VIII Relative to the Laying of Automatic Submarine Contact Mines art. 1(3), Oct 18, 1907,36 Stat. 2332, T.S. No. 541 [hereinafter Hague Convention VIII]. See also SAN REmo Manual, above note 52, 979.

77 Hague Convention VIII, above note 76, art. 1(1). See also SAN REMO MANUAL, above note 52, $₫$ 82(b). 
shipping after their use, are unlikely to present a significant hurdle to the development and employment of UMSs. However, account must be taken of them during the review process.

It is important to understand that a weapon or weapon system will pass legal review so long as it can meet the required standards in the environment(s) into which it is intended to be introduced. This means that the characteristics of that environment can be taken into consideration. Thus, for example, if civilians and civilian ships (and submarines) are usually absent from areas where a UMS is likely to be used, as they are in much of the sea, then that is a relevant factor in assessing the risk of striking military objectives and civilians or civilian objects without distinction. It must be cautioned, however, that the actual proximity of civilians and civilian ships has to be taken into consideration when employing the systems, for instance in a busy sea lane or international strait. In other words, it is necessary to distinguish the per se lawfulness of a UMS on the basis that there are circumstances in which it is capable of distinction, from its lawfulness, or lack thereof, in a specific engagement.

\section{Conduct of Hostilities}

It is the subsequent use of a UMS that has passed legal review that is most likely to run afoul of the law. Of central importance in this respect are the prohibition of attack on persons or objects not constituting lawful military objectives (a category that has unique characteristics under the law of naval warfare), the prohibition on conducting an attack indiscriminately, the rule of proportionality, and the requirement to take precautions in attack. In treaty law, these rules are found in Additional Protocol I. However, the Section of the Protocol in which they appear is only applicable to attacks conducted from the sea when they are directed against objectives on land or where civilians on land may be affected. ${ }^{78}$ Most attacks likely to be conducted by a UMS, at least in the present state of the technology, will be against other maritime systems, for instance by mining or direct attack, and will accordingly not be governed directly by Additional Protocol I conduct of hostilities rules. Despite this fact, it is widely accepted that customary law counterparts of the rules do apply at sea. ${ }^{79}$

As with any other naval engagement, a party to the conflict employing a UMS to conduct an attack must assess whether that attack is directed at a lawful target. ${ }^{80}$ A special regime for 'military objectives' exists at sea. Certain ships are immune from direct attack, protected from indiscriminate attack, included in proportionality calculations, and considered vis-à-vis the requirement to take precautions in attack. These include enemy:

(a) hospital ships;

(b) small craft used for coastal rescue operations and other medical transports;

(c) vessels granted safe conduct by agreement between the belligerent parties including:

(i) cartel vessels, e.g., vessels designated for and engaged in the transport of prisoners of war;

\footnotetext{
78 Additional Protocol I, above note 71, art. 49(3).

79 SAN REMO MANUAL, above note 52, 9 甲 40, 42(b)(i), 46.

80 SAN REMo MANUAL, above note 52, 9 42(b)(i). See also CIHL STUDy, above note 62 rules 11-12; Additional Protocol I, above note 71, art. 51(4). Protected ships may sometimes lose their protection if they fail to meet the associated requirements. SAN REMO MANUAL, above note 52, 19 48-49; Convention (II) for the Amelioration of the Condition of the Wounded, Sick, and Shipwrecked Members of Armed Forces at Sea art. 34, Aug. 12, 1949, 6 U.S.T. 3217 , 75 U.N.T.S. 85 [hereinafter GC II] (providing specifically for the loss of protection by hospital ships).
} 
(ii) vessels engaged in humanitarian missions, including vessels carrying supplies indispensable to the survival of the civilian population, and vessels engaged in relief actions and rescue operations;

(d) vessels engaged in transporting cultural property under special protection;

(e) passenger vessels when engaged only in carrying civilian passengers;

(f) vessels charged with religious, non-military scientific or philanthropic missions, vessels collecting scientific data of likely military applications are not protected;

(g) small coastal fishing vessels and small boats engaged in local coastal trade, but they are subject to the regulations of a belligerent naval commander operating in the area and to inspection;

(h) vessels designated or adapted exclusively for responding to pollution incidents in the marine environment;

(i) vessels which have surrendered; [and]

(j) life rafts and life boats. ${ }^{81}$

Unlike land warfare, however, a number of civilian ships may be attacked. Enemy merchant vessels become military objectives if they are involved in belligerent activities on behalf of the enemy, such as cutting undersea cables; are performing the duties of an auxiliary to enemy forces, as with transporting troops; gather intelligence for the enemy, perform an early warning function, or contribute to enemy command and control; sail in a convoy escorted by enemy warships or aircraft; are armed at a level that poses a risk to warships; or make an effective contribution to the enemy's military operations in some other way. ${ }^{82}$ Enemy merchant vessels may also be attacked if they refuse an order to stop, or actively resist visit, search, or capture. ${ }^{83}$

In all these cases, UMSs could be used to conduct the attack, so long as other legal requirements were met. As an example, if a convoy of enemy warships and enemy merchant vessels is detected far out to sea, an armed UMS would be an ideal means with which to conduct the attack, since the risk to own forces would be minimized and there would be no requirement to distinguish amongst the various vessels in the convoy as they all would be subject to attack. For the near term, the likelier use of the systems is for identifying and/or tracking targets for attack by other means. Such operations raise no unique legal issues. On the contrary, as explained below, the use of a UMS may be required as a feasible precaution in attack by way of verifying the nature of the potential target.

Pursuant to the law of naval warfare, enemy merchant vessels, with some exceptions, ${ }^{84}$ may be captured beyond neutral waters for adjudication in a prize proceeding. ${ }^{85}$ If there is any doubt as to their status, they may be visited and searched, so long as there are reasonable grounds for suspecting

81 SAN REMO MANUAL, above note 52, \ 47; GC II, above note 80, arts. 21, 22, 27, 38, (providing for protection of hospital ships and medical transports); Convention for the Protection of Cultural Property in the Event of Armed Conflict art, 12(3), May 14, 1954, 249 U.N.T.S. 240 (providing for the protection of vessels carrying certain cultural property); Convention No. XI Relative to Certain Restrictions with Regard to the Exercise of the Right of Capture in Naval War arts. 3, 4, Oct 18, 1907, 36 Stat. 2396, T.S. No. 544 (providing for the protection of small coastal fishing vessels and small boats engaged in local coastal trade, and of vessels charged with religious, scientific or philanthropic missions).

82 SAN REMO MANUAL, above note 52, 960.

83 SAN REMO MANUAL, above note 52, $960(\mathrm{e})$.

84 SAN REMO MANUAL, above note 52, $₫$ 136; GC II, above note 80, 21, 22, 27, 38, (providing for protection of hospital ships and medical transports); Additional Protocol I, above note 71, art. 70 (providing for the protection of relief consignments).

85 SAN REMO MANUAL, above note 52, \ 135; U.S. COMMANDER’s HANDBOOK, above note 59, 9 8.6.2.1. 
they are subject to capture. ${ }^{86}$ The right of visit and search, as well as capture, also applies to ships that: are flying a neutral flag when the commander of a warship suspects it of having enemy character; are transporting contraband; are acting as a transport for enemy forces; are operating under some form of enemy control; have failed to present proper and authentic documents; are violating regulations set forth by the belligerent within the immediate area of naval operations; or are attempting to breach a blockade. ${ }^{87}$

Unmanned maritime systems could conduct or facilitate these operations in various circumstances. Recall, for instance, that UMSs may be employed during a boarding operation to monitor all aspects of the ship being boarded, thereby enhancing the security and situational awareness of the boarding team. Furthermore, sensors on the UMS might be able to examine the ship's internal contents to identify and locate contraband. Of course, unmanned systems would be extremely useful as a force multiplier in monitoring blockades or compliance with regulations issued by military commanders in the immediate zone of operations.

The question of whether a UMS is per se capable of being directed against a military objective, that is, whether it is can be used discriminately, should have been addressed during the weapon review process. However, even if the system is capable of being used discriminately, the operator is prohibited from employing it without directing it against a lawful target. ${ }^{88}$ An example of indiscriminate use would be sending a USV incapable of distinguishing a warship from a civilian vessel into a dual-use port. In that the USV will attack any vessels it locates there, and because the port is being used by both military and civilian ships, the attack would be indiscriminate.

Similarly, it would be unlawful to use a UMS to monitor shipping lanes used by both civilian and military ships and attack any ship passing through them. This is so even though warships may be in the lanes at times, and sinking one would amount to a significant military advantage. It is the fact that the system is not distinguishing between ships that are, and are not, subject to attack, that renders the use of the UMS unlawful. It must be cautioned, however, that it is not a violation of the law of armed conflict to use a UMS that cannot distinguish lawful from unlawful targets, without more. Rather, it is the use of such a system in circumstances where it is likely to encounter and attack both that is unlawful.

An issue related to the obligation to distinguish arises from the fact that enemy vessels that have surrendered are exempt from attack. ${ }^{89}$ Recognizing surrender would be an especially significant challenge for autonomous systems, requiring as it does the interpretation of complex behaviour. However, while the text of Article 41(2)(b) of Additional Protocol I provides for the protection of those who 'clearly [express] an intention to surrender', it is well-accepted that the surrender must be evident to the opposing side. This is true as well in the maritime context. ${ }^{90}$ The United States goes further, taking the position that a surrender need only be accepted when it is feasible for the opposing side to do so. ${ }^{91}$ As a result, it is unlikely to be an issue if UMSs are unable to recognize

\footnotetext{
86 SAN REMO MANUAL, above note 52, $₫ 118$.

87 SAN REMO MANUAL, above note 52, $\uparrow$ ๆ 114, 146.

88 SAN REMO MANUAL, above note 52, $\mathbb{\uparrow} 41$.

${ }^{89}$ Additional Protocol I, above note 71, art. 41(2)(b); SAN REMO MANUAL, above note 52, 947 (i).

90 SAN REMO MANUAL, above note 52, 1 甲 47.56-47.57.

${ }^{91}$ U.S. DoD MANUAL, above note 44, \5.10.3.3. See also CIHL STUDY, above note 62, 168-69.
} 
surrender, although a UMS must be redirected or recalled, if to do so is feasible, so as not to attack a formerly lawful target that has offered its surrender.

The rule of proportionality likewise applies in naval warfare. ${ }^{92}$ It prohibits an attack in which the expected incidental injury to civilians and collateral damage to civilian objects is excessive relative to the anticipated military advantage of the attack. The fact that a UMS conducts an engagement presents no unique legal obstacles so long as the engagement involves a man in or on the loop. In such circumstances, the UMS is merely a weapon system like any other, in which assessments of proportionality are made by the human considering all relevant circumstances then holding.

Compliance with the rule of proportionality may be problematic when an autonomous UMS is unable to assess the expected collateral damage or anticipated military advantage likely to result in the attendant circumstances. ${ }^{93}$ However, this would not necessarily render an engagement unlawful because the UMS could be programmed to only attack under certain conditions. For instance, USVs might be programmed just to engage those submarines having the distinct signature, acoustic or otherwise, of a class, or hull, from the enemy's fleet. So long as their weapons were expected to affect only underwater objects, then, depending on where and for how long the USVs performed this function, their usage would be unlikely to raise proportionality questions. Or consider UMSs that are able to identify enemy surface warships with a high degree of reliability, but which are programmed not to attack if another ship, not meeting the target criteria, is within the destructive radius of the weapon(s) to be used. As a rule, the vast areas involved and the quality of sensor technologies are such that it is in naval warfare that unmanned systems will present the fewest proportionality challenges.

It is in relation to the requirement to take precautions in attack that UMSs may make their greatest contribution to advancing the protective effects of international humanitarian law. Additional Protocol I includes a specific provision on such precautions during maritime operations. According to Article 57(4), 'In the conduct of military operations at sea or in the air, each Party to the conflict shall, in conformity with its rights and duties under the rules of international law applicable in armed conflict, take all reasonable precautions to avoid losses of civilian lives and damage to civilian objects. ${ }^{94}$

This is a curious provision as it appears in a Section that, as noted, is applicable in the maritime context only to sea-to-land attacks. The ICRC Commentary to the Article speculates that paragraph 4 is meant to address situations in which the attack is not against land based targets, but rather some effect of the attack manifests there. ${ }^{95}$ Article 57(4) also uses the term 'reasonable' rather that that used in the other aspects of the Article, 'feasible', thereby begging the question of whether there is a difference.

These issues need not detain the discussion. Whatever the intent behind the paragraph and word choice, it is widely accepted today that Article 57 fairly replicates the customary law precautions

\footnotetext{
92 SAN REMO MANUAL, above note 52, $146(\mathrm{~d})$.

93 See discussion of this issue in Michael N. Schmitt and Jeffrey C. Thurnher, "Out of the Loop": Autonomous Weapon Systems and the Law of Armed Conflict, 4 Harvard NATIONAL SECURiTy JOURnAL 231, 253-257 (2013).

94 Additional Protocol I, above note 71, art. 57(4).

95 Commentary on the Additional Protocols of 8 June 1977 to the Geneva Conventions of 12 August 1949, ๆ 2230-33 (Yves Sandoz, Christophe Swinarski \& Bruno Zimmermann eds., 1987).
} 
requirements that generally apply to naval warfare. ${ }^{96}$ These are that the attacker must do everything feasible to verify that the target is a lawful one; choose means and methods of warfare, as well as targets, that will result in the least harm to civilians and civilian objects without sacrificing military advantage; cancel or suspend an attack if it becomes apparent that the rule of proportionality will be violated or other violations of the law of armed conflict will result; and provide an effective warning of an attack that may affect the civilian population when circumstances so permit.

The precautions in attack requirements have several implications in the UMS context. Of central importance is the verification obligation. Given that UMSs are unmanned, the systems may be deployed to the proximity of potential targets to verify their status and actions, as well as to assess any potential for collateral damage, without endangering one's own personnel or other critical assets. To the extent such systems are available to a naval commander, and their use is operationally feasible in the circumstances, they must be employed if doing so would contribute meaningfully to verification of a target. Likewise, they may be used to monitor an engagement to, again, ensure continuing adherence to the law of armed conflict.

The precautions in attack obligation to select means of warfare is also relevant. There may be situations where unmanned systems can achieve the same objective as an attack conducted directly by a warship or other manned system, but at lower risk to civilians. Consider an enemy merchant vessel with civilians aboard that is attempting to evade lawful capture or a neutral ship that is in the process of breaching a blockade. A UUV might be able to disable the ships by, for example, damaging or disabling their propellers. If this is so, the UUV would have to be used, if feasible in the circumstances, in lieu of a warship armed with weapon systems likely to cause greater collateral damage or incidental injury. Additionally, the requirement to select the means of warfare least likely to cause civilians and civilian objects harm may determine the type of weapon deployed from a UMS. In the example above, it could drive selection of a weapon likely to disable, rather than sink, the ships.

USVs are likely to offer an effective means of warning ships. Recall that an attempt must be made to capture certain ships before they are attacked and that warships have an obligation to conduct a visit and search in various situations where the status of a ship is uncertain. USVs could be employed to warn the ships concerned that if they resist capture or fail to cooperate in the visit (and, possibly, search), they open themselves to attack. Such warnings are important in that merchant ships may carry civilians. Moreover, warning is imperative in the case of a ship with uncertain status because the very fact that status is uncertain evidences doubt, and doubt imposes a presumption of civilian status. $^{97}$ It is only when the ship resists visit and search that the doubt is rebutted as a matter of law. Additionally, naval forces have a right to control the immediate area of operations, ${ }^{98}$ and USVs would be helpful in warning away vessels that might be placed at risk by their presence therein.

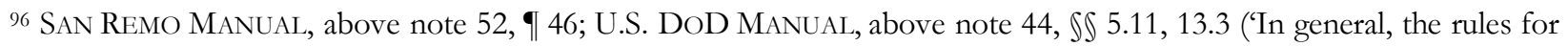
conducting attacks, such as bombardments, by naval forces are the same as those for land or air forces.'); GERMAN COMMANDER'S HANDBOOK, above note 58, at 165-66.

${ }^{97}$ For instance, see SAn Remo MAnual, above note 52, 9 58. See also CIHL STUdy, above note 62, 35-36. But see U.S. DOD MANUAL, above note 44, \5.4.3.2.

${ }^{9}$ SAN REMO MANUAL, above note 52, $\mathbf{q} 108$.
} 


\section{The Law of Neutrality}

Consideration of neutrality issues with respect to UMSs centres on two issues: navigational prerogatives and belligerent operations in neutral territory, including the territorial sea. With respect to the former, neutral waters include internal waters, the territorial sea, and archipelagic waters. ${ }^{99}$ During an international armed conflict, UMSs may be used by belligerent ships, when doing so is part of their normal mode of operation, while in either transit passage through an international strait or archipelagic sealane passage. Similarly, neutral ships may use UMSs as they transit belligerent international straits and archipelagic waters. ${ }^{100}$ If they are considered ships, or otherwise granted navigational rights, then they would be entitled to conduct transit passage and archipelagic sealane passage in their own right. Despite the existence of an armed conflict, neutral States are precluded from suspending or impeding the rights of transit and archipelagic sea lanes passage. ${ }^{101}$

The treatment of territorial waters in the law of neutrality differs from that set forth in the law of the sea. During an armed conflict, neutral coastal States may, but are not required to, allow 'mere passage' through their territorial sea by belligerent warships. ${ }^{102}$ Should mere passage be allowed, the neutral State is entitled to impose conditions and restrictions thereon. Any such conditions and restrictions must be applied equally to the warships of all parties to the conflict. ${ }^{103}$

As discussed above, unmanned systems associated with a warship are bound by the same rules as the warship. While those operating independently do not currently qualify as warships, they would, were they to be considered as having navigational rights, benefit from the mere passage regime. That said, the neutral coastal State would be within its rights to bar such passage, either for UMSs in general, or for particular types, such as those carrying weapons, so long as it does not discriminate between belligerents.

On whatever basis UMSs may be present in neutral waters, the law of neutrality places strict limitations on their activities, especially engaging in 'hostile actions'. These include, but are not limited to:

(a) attack on or capture of persons or objects located in, on or over neutral waters or territory;

(b) use as a base of operations, including attack on or capture of persons or objects located outside neutral waters, if the attack or seizure is conducted by belligerent forces located in, on or over neutral waters;

(c) laying of mines; or

(d) visit, search, diversion or capture. ${ }^{104}$

It is important to emphasize that the limitations apply with respect to taking actions against an adversary's ships that are also engaged in mere passage. Of course, UMSs could, as discussed, conduct or facilitate the forbidden activities, as in the case of laying mines or participating in the visit and search of a merchant ship. Should they do so, the party to the conflict to whom they belong

\footnotetext{
99 SAN REMO MANUAL, above note 52, $₫ 14$.

100 SAN REMO MANUAL, above note 52, 9 - 23-30.

101 SAN REMO MANUAL, above note 52, 929.

102 Convention No. XIII Concerning the Rights and Duties of Neutral Powers in Naval War arts. 9-10, Oct. 18, 1907, 36 Stat. 2415, T.S. No. 545 [hereinafter Hague Convention XIII].

103 Hague Convention XIII, above note 102, art. 9.

104 SAN REMO MANUAL, above note 52, 1 16; Hague Convention XIII, above note 102, art. 2.
} 
will be in breach of the coastal State's neutrality. The prohibitions also extend to hostile activities while in transit through or under a neutral international strait or neutral archipelagic sealane. ${ }^{105}$

Despite the restrictions, warships may take defensive measures for their own security while passing through these waters. It is well settled that doing so includes the launching of aircraft and engaging in acoustic and electronic surveillance. This being so, there is no basis for denying them the right to use unmanned systems to ensure security, for instance, by monitoring activities of enemy ships in the area. ${ }^{106}$ On the contrary, UMSs would be invaluable in ensuring the security of the warships in the permitted forms of passage.

Neutral States also bear obligations under the law of neutrality. Of primary importance is the duty to prevent or halt belligerent activities that violate their neutrality, such as the conduct of hostilities. ${ }^{107}$ Accordingly, should a UMS engage in the hostile actions set forth above, or any other activity qualifying as the exercise of a belligerent right, the neutral State would be obliged to put an end to the conduct. Indeed, the neutral State could resort to force if necessary to meet this obligation. If it fails to halt the exercise of belligerent rights in its waters by a UMS, the opposing party to the conflict would be entitled to do so itself, including the use of force where strictly necessary. ${ }^{108}$

Unmanned maritime systems may be used by belligerents in the exclusive economic zone and the high seas for any otherwise lawful purpose related to the armed conflict. When engaging in such activities, 'due regard' must be paid to the rights of neutral shipping and other neutral interests in those areas. For instance, belligerents must pay due regard to the rights of the coastal State to explore and exploit natural resources within its exclusive economic zone and continental shelf, as well as act in a manner consistent with the preservation of the maritime environment. ${ }^{109}$ Similarly, on the high seas, the use of UMSs must respect neutral States' rights to explore and exploit the natural resources of the sea-bed, ocean floor, and subsoil, and must avoid causing any damage to cables and pipelines on the sea-bed, except for those exclusively serving an enemy State. ${ }^{110}$ The reference to avoiding damage to cables is particularly pertinent to UMSs, which might plausibly be used to damage, or otherwise interfere with, submarine communication cables.

\section{Conclusions}

Recent events in the South China Sea highlight the importance of understanding how international law affects unmanned maritime systems. The category comprising UMSs is broad and growing in its scope. It includes devices that operate both on and under the sea, and which may be used for a diverse range of tasks, from oceanographic survey to the conduct of hostilities. The status of these systems is an important question, for it entails important rights and obligations both in peacetime and during armed conflict. The matter of status, however, remains unresolved. While there is a plausible argument for affording UMSs navigational rights, either as ships or as a special case, it is

\footnotetext{
105 SAN REMO MANUAL, above note 52, $₫ 15$.

106 SAN REMO MANUAL, above note 52, $₫ 30$.

107 SAN Remo MANUAL, above note 52, 9 1 15, 22. These obligations are drawn, in part, from Hague Convention XIII, above note 102, art. 25. See also U.S. DOD MANUAL, above note 44, \15.3.2.

108 SAN REMO MANUAL, above note 52, 9 22; U.S. DOD MANUAL, above note 44, \15.4.2.

109 SAN REMO MANUAL, above note 52, 934.

110 SAN REMO MANUAL, above note 52, ๆ $36-37$.
} 
too early to reach a definitive conclusion. Furthermore, while the conditions for warship status currently appear unattainable for UMSs, it is conceivable that the law on point will evolve through practice and expressions of opinio juris.

Irrespective of the unsettled issues surrounding status, there is no question that UMSs may be lawfully-and usefully-employed both in peacetime and during armed conflict. Even without rights of their own, they may be deployed by ships and warships to perform numerous and diverse functions. In particular, as a means of warfare, they may be used during armed conflict like any other weapon. Equally, however, they are subject to the same duties and obligations that attach to the ships from which they are employed, as well as those rules bearing on weapon systems and their use. The fundamental point is that, despite the novelty of UMSs, States must apply the existing law to them in good faith. 